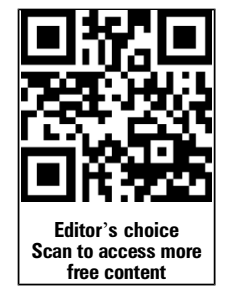

Correspondence to

Professor John McMillan, Bioethics Centre, Division of Health Sciences, University of Otago, PO Box 913, Dunedin, Otago 9054, New Zealand; john.mcmillan@otago.ac.nz

Received 16 August 2012 Revised 10 March 2013 Accepted 10 April 2013 Published Online First 11 May 2013

\title{
The kindest cut? Surgical castration, sex offenders and coercive offers
}

\author{
John McMillan
}

\section{ABSTRACT}

The European Committee for the Prevention of Torture and Inhuman or Degrading Treatment or Punishment (CPT) have conducted visits and written reports criticising the surgical castration of sex offenders in the Czech Republic and Germany. They claim that surgical castration is degrading treatment and have called for an immediate end to this practice. The Czech and German governments have published rebuttals of these criticisms. The rebuttals cite evidence about clinical effectiveness and point out this is an intervention that must be requested by the sex offender and cannot occur without informed consent. This article considers a number of relevant arguments that are not discussed in these reports but which are central to how we might assess this practice. First, the article discusses the possible ways in which sex offenders could be coerced into castration and whether this is a decisive moral problem. Then, it considers a number of issues relevant to determining whether sex offenders are harmed by physical castration. The article concludes by arguing that sex offenders should not be coerced into castration, be that via threats or offers, but that there is no reason to think that this is occurring in the Czech Republic or Germany. In some cases, castration might be useful for reconfiguring a life that has gone badly awry and where there is no coercion, the European Committee for the Prevention of Torture and Inhuman or Degrading Treatment or Punishment are mistaken about this being degrading treatment.

For Brutus, as you know, was Caesar's angel. Judge, O you gods, how dearly Caesar lov'd him! This was the most unkindest cut of all; For when the noble Caesar saw him stab, Ingratitude, more strong than traitors' arms, Quite vanquish'd him: then burst his mighty heart....

...there's no doubt that in old age you get a great deal of peace and freedom from things like sex. When the desires lose their intensity and ease up, then what happens is absolutely as Sophocles described-freedom from a great many demented masters. $^{2}$

\section{INTRODUCTION}

Shakespeare describes the way in which betrayal can fracture important relationships in a deeply harmful way. Those who are victims of sexual abuse, particularly within the context of family relationships, can be damaged deeply by this betrayal. This is not to understate the harmfulness of the act itself, nor the other psychological harms that follow from it, but it is clear that sexual abuse often does violate trust in a profound way. Our obligations to those who commit offences of this kind and what we should do to help minimise the risk of this kind of harm being repeated therefore are important ethical questions.

In book 1 of the Republic Socrates ruminates with Cephalus about what old age will hold for him. It is as true now as it was then that for many (but by no means all), advancing years bring a release from motives and desires that were once all encompassing. When people experience changes of this kind we tend to view them as being part of the fabric of a person's life and consistent with maturation and continued development into latter years.

However, the availability of chemical and surgical means for altering motives and desires has forced us to confront the possibility of more rapid changes than is typically the case for those brought about via aging and maturation. There is an extensive literature about the ethics of pharmacological and surgical enhancement. ${ }^{3}{ }^{4}$ However, some of the oldest and most drastic methods of altering agency present these issues in an even more stark fashion. It is hard to see the physical or chemical castration of sex offenders as 'enhancements' but there's no doubt that that they are radical solutions to difficult problems that have the effect of causing profound changes to a person.

Should we, like Cephalus, see the changes brought about by the diminishment of passion as freeing or does castration always physically and psychologically violate agents? This is a general question but one that has been answered differently depending upon the place and time. Surgical castration was at the centre of a heated exchange within the European Union between the European Committee for the Prevention of Torture and Inhuman or Degrading Treatment or Punishment $(\mathrm{CPT})^{5}{ }^{6}$ and the governments of the Czech Republic $^{7}$ and Germany. ${ }^{8}$ The answer to this question and the position taken by these institutions depends upon ethical argument and upon the history and social context of castration. I will begin by providing a description of the procedure and some social and political factors that shape the perception of castration. Then I will consider the efficacy of castration for preventing reoffending. Consent is the primary ethical problem discussed by the CPT and I will suggest that they are right to emphasise its importance.

A major ethical worry is that when castration is mentioned as an option to imprisoned sex offenders and is the only way that they are likely to be released from prison, this will be a coercive offer. I will discuss some objections that have been levelled at the coherence of 'coercive offers.' Then, I will defend 'coercive offers' and suggest that if 
the possibility of castration is presented to sex offenders in such a way that it 'coerces' them, that would be a serious wrong. However, there are reasons to suppose that when castration is mentioned as a possibility within the Czech Republic and particularly within Germany, no attempt to coerce sex offenders is made.

The second part of the article considers a number of morally relevant issues, including whether agreeing to castration is an appropriate use of a liberty and the role that castration might have for reconfiguring the developmental trajectories of some sex offenders.

\section{THE CPT AND CASTRATION}

The CPT's strongly worded criticisms of the physical castration of convicted sex offenders in the Czech Republic and the robust and direct rebuttal of these criticisms by the Czech government are expressed in unusually forthright terms. The rebuttal from the German government is, perhaps, a little more conciliatory in its tone, but is nonetheless direct in defending their practices. This is no doubt due in part to the nature of the CPT's brief, no reasonable nation state, especially one that has been admitted to the European Union and is a signatory to the European Convention on Human Rights, would be happy about the CPT's view that the '...surgical castration of detained sex offenders amounts to degrading treatment. ${ }^{5}$

While the CPT based this judgment upon a number of specific worries about practices within these countries, it is important to not neglect the European context within which these institutions are operating. As the CPT note 'Until 30 years ago, surgical castration was an accepted medical intervention in several Council of Europe member States in the treatment of sex offenders'. 5 Sweden, and the Netherlands among others, have offered surgical castration to sex offenders. This, on its own, is not sufficient for explaining the sensitivity of this topic within Europe, but other historical events, linked to this practice are: the compulsory castration of sex offenders in Nazi Germany ${ }^{9}$ and the historical links between castration, sterilisation and eugenics in many European countries. The Czech and German methods for managing sex offenders run the risk of reminding many within Europe of historical events that should not be repeated.

Another possible resonance, which is worth some consideration, is the way that psychiatry was used as a system of social control within the USSR. While Eastern European states have liberal mental health law and modern psychiatric practices, the exploitation of psychiatry to further the ends of totalitarian regimes is fairly recent history. ${ }^{10}$ It is also relevant that historically, physical castration has been a punishment for sex crimes and to further other ends such as creating eunuchs for harems and castrati thought to be socially as opposed to medically, valuable. $^{11}$

Given these historical, social and political considerations, it is not surprising that this has generated a significant amount of controversy within Europe. However, discussing the historical and political background won't take us far in reaching an ethically defensible position on castration. While there are some apparent similarities with historical events that should give us reason to pause, more needs to be said about the ethical considerations that are relevant to physical castration.

\section{TESTICULAR PULPECTOMY}

It is important to be clear that the technique used in the Czech Republic and Germany is 'testicular pulpectomy', which doesn't, as some of the more sensational media reports have suggested, involve the removal of the testes. ${ }^{12}$ Instead, parts of the core of the testes are removed with the result there is relatively little in the way of physical disfigurement, at least at a visible level. There are a number of side effects including infertility, an increased risk of osteoporosis, and a general feminisation of the body, that is, an increase in breast tissue and decreased body hair. ${ }^{5}$ While testosterone levels are significantly reduced, the body still produces some testosterone.

\section{EFFICACY IN PREVENTING REOFFENDING}

Neither the CPT nor the Czech government go into much detail about whether physical castration is an effective way to prevent sex offenders from reoffending or whether it improves their lives. The CPT simply claim that '...surgical castration is no longer a generally accepted medical intervention in the treatment of sex offenders. ${ }^{5}$ and thereby imply that Czech physicians are deviating from what would be medically acceptable elsewhere. This, on its own, is not a sufficient reason for insisting that this practice must cease. The politically charged nature of castration might explain the fact that it is not offered in many other places and this could be consistent with it being an effective way to prevent further offending and improve the lives of sex offenders.

The Czech government attempt to rebut this claim in a similarly unconvincing way. They say

...this is a purely professional issue... Castration is considered with respect to men who cannot manage their sexual instincts and are sexually aggressive. Surgical castrations are performed on the basis of other than psychiatric indications (particularly in the case of oncological diseases). ${ }^{7}$

Citing professional judgment as a reason in this context isn't a good response: the politically charged nature of this issue means that evidence should be provided in favour of this being an effective treatment. Their point that the operation itself is one that is used to control medical conditions such as testicular cancer does provide some reassurance that the technique itself is well developed and something for which the relevant surgical expertise exists. However, it doesn't address the more fundamental worry about effectiveness.

In Wille and Beier's comparison of castrated and noncastrated sex offenders they provide what is probably strongest evidence for an improvement in reoffending rates. ${ }^{13}$ They compared 104 men (about 20-25\% of all men who were castrated in the 1970s in the Federal Republic of Germany) with a group of sex offenders who had applied for surgery during the same period but did not follow through with the surgery. They found that the sexual recidivism rate for the first group was $3 \% \mathrm{com}$ pared with $45 \%$ in the group who had not had the surgery. While these results appear to show a very dramatic difference between the two groups we might be cautious about the quality of the controls: they were men who had been counselled about the possibility of castration but had decided against the operation. It might be that their decision to not follow through with the operation was because of a lack of resolve to control their offending, whereas men who were prepared to have this operation might have been more willing to do whatever it takes to change their behaviour. Nonetheless, the reported reoffending rate of $3 \%$ from over a 100 men gives us a good reason to suppose that in some contexts castration has been shown to be effective.

Losel and Schmucker conducted what is probably the most exhaustive meta-analysis of reoffending and castration to date and found that treated offenders showed 37\% less recidivism 
than controls. ${ }^{14}$ They included chemical and physical castration within the 'treated' category so their study doesn't shed any light on the comparative effectiveness of these methods. They also found that surgical and hormonal treatments were more effective than psychosocial interventions.

Another reason for supposing that castration is at least reasonably effective at preventing reoffending, is because many sex offenders, who would otherwise be detained indefinitely, often leave the hospital 6-12 months after castration, following psychotherapy and assessment. Given the responsibility that these institutions have in predicting and preventing reoffending, it is reasonable to suppose that they are competent in their assessment that castrated sex offenders who are released are safe enough to be released back into the community.

Even though there seem to be some good reasons to think that castration is effective at helping prevent further offending, this on its own does not answer the charge that this is an instance where psychiatry fulfils a social role but masquerades as treating illness. This antipsychiatric objection is important and it is another reason why it is important to examine the voluntariness of these offers. In the next section I will explain a second major ethical problem that derives from the connection between castration and the possibility of being released from an indefinite detention.

\section{CONSENT}

The CPT raised a number of concerns about the quality of the consent to castration given by sex offenders. The first concern is that for many sex offenders in the Czech Republic, there were few other options for treatment apart from castration and the CPT cites one case where a prisoner had no treatment for 19 years. ${ }^{5}$ Given the permanent and radical nature of this intervention it's reasonable to expect that prisoners would have more than one therapeutic option on the table. In Germany far fewer men have been castrated and it is more likely that they will have had other therapeutic options. ${ }^{8}$

A second concern is that the CPT interviewed sex offenders who claimed they were not adequately informed about side effects of physical castration such as osteoporosis. Once again, if this genuinely is the case then it's an ethical deficiency in the way that the Czech services are managed, but not necessarily an in-principle objection to physical castration.

The third and perhaps most significant consent-based objection is that

In practically all the cases, these patients indicated that their application was at least instigated by fear of long-term detention. $^{5}$

Given the absence of any other treatment options and the likelihood that castration is, for many of these men, the only way that they will be released back into the community, the status of this decision as a genuine expression of their autonomy is questionable. In their response to the CPT, the significance of this point doesn't seem to have registered with the Czech Government.

Therapeutic testicular pulpectomies, which may be carried out in the Czech Republic, are performed upon the written request of an adult man, and the establishment of an expert commission is always required for the professional assessment of reasons. Prior to the performance of such intervention, the patient must express his consent with its performance. ${ }^{5}$

If the patient is given a choice between an undesirable option and another option that is so undesirable that it is not an option at all, then the written request and consent of the patient do not exhaust all of the relevant moral considerations. Even if there were no question marks over the information provided to these men, their understanding of it and their competence, if it's not a voluntary decision, it's not valid consent. The third major concern about the choice that these men are given is that their consent might be coerced.

\section{COERCIVE THREATS}

Coercion is usually thought of as something that limits freedom and in cases of consent renders a person's agreement involuntary. There are many accounts of coercion but Robert Nozick's classic formulation is an useful place to start for unpacking this issue. For Nozick, P coerces Q when:

1. P aims to keep $\mathrm{Q}$ from choosing to perform action $\mathrm{A}$;

2. $\mathrm{P}$ communicates a claim to $\mathrm{Q}$;

3. P's claim indicates that if $\mathrm{Q}$ performs $\mathrm{A}$, then $\mathrm{P}$ will bring about some consequence that would make Q's A-ing less desirable to $\mathrm{Q}$ than Q's not A-ing;

4. P's claim is credible to $\mathrm{Q}$;

5. Q does not do A;

6. Part of Q's reason for not doing A is to lessen the likelihood that $\mathrm{P}$ will bring about the consequence announced in (3). ${ }^{15}$

A point to note about Nozick's analysis is that he thinks that coercion exists only when the coercer is successful (condition 5). Of course there are also cases where a coercee might resist an attempt at coercion but Nozick can plausibly say in that kind of case we might describe the coercee as being 'coercive' rather than having coerced or succeeded in coercion. Nozick's conditions are plausible and do seem to capture what we mean much of the time when we describe an action as coercive, however it is important to bear in mind that what he generates is an account of coercive threats. We're all familiar with the 'money or your life' scenario and would agree that this is coercive and a threat.

Being clear about the conditions under which we might describe something as a coercive threat is useful for unpacking some coercive practices in a mental health context, where it is sometimes thought necessary to find ways of getting people to do things that they would otherwise not. There is a temptation in this context to equate compulsion with coercion and keeping this distinct helps to clarify the different ways that they override freedom. ${ }^{16}{ }^{17}$ However, most of Nozick's conditions would not be satisfied if a psychiatrist or hospital told a sex offender about the possibility of them being released if they consent to physical castration. When a psychiatrist suggests castration as an option, there need not be any restriction of his choice, nor do they have to threaten to bring about something unpleasant if he doesn't choose to be castrated: choosing to not be castrated is unlikely to make any difference to whether he continues to be detained.

Of course, a great deal turns on how the psychiatrist discusses this with a sex offender and their intention in doing so. If they were to say 'you should think carefully about castration or else we will make sure that you are not released for a very long time' with the intention that the sex offender sees this as an offer that they cannot refuse, then it would have reduced their options and is therefore a coercive threat.

However, there is no reason to suppose, especially given the requirement in the Czech and German systems that the request for castration has to be initiated by the sex offender, that it is anything other than an offer and increases the range of options available to the sex offender. In such cases, this is enhancing rather than reducing the sex offender's freedom. Nonetheless, it 
seems, intuitively, as if agreeing to be castrated under these conditions makes the decision coerced in some way. If this is an instance of coercion, it has to be a coercive offer: the idea that some offers that appear to increase the range of options can in fact coerce.

It might be objected that the psychiatrist herself is not coercing the sex offender; rather it is the state via the legal system that will continue to detain him. That objection is consistent with the remedy that CPT has sought in the Czech Republic and Germany, which is that the practice should be stopped by the abolishment of the legal framework that makes this possible. The CPT did not claim that psychiatrists who raise the possibility of castration with sex offenders should be held to account.

While it is important to look at the broader framework within which practices such as this occur, it is also important to not lose sight of that fact that psychiatrists act within a legal framework. They are empowered and restricted in what they can do by the professional guidelines and legal frameworks which regulate their practice. It is also a fact that psychiatrists and therapists are likely to be the people who mention castration as a possibility and they are therefore those who are most likely to be able frame this as a threat or an offer. In effect, they are agencies of the state, even if they themselves do not have a say in whether or not they actively bring about the undesired outcome.

\section{COERCIVE OFFERS}

There is a good reason for being sceptical about whether 'coercive offers' are possible and by implication whether it is possible for sex offenders who are castrated to be coerced in that way. Threats attempt to remove options by making at least one of them undesirable and therefore sit more naturally alongside the idea of coercion, which also implies that choices are rendered involuntary. Offers, on the other hand, tend to create options that otherwise would not exist. How is it possible for something to create an option and remove an option at the same time?

The most elegant and convincing examples of coercive offers are those discussed by Joel Feinberg in Harm to Self. ${ }^{18}$ One of them, 'the governor and the prisoner', seems particularly relevant to sex offenders and castration. Consider

\section{... a governor's proposal to a prisoner on death row that his sen- tence be commuted if and only if he agrees to be a subject in a medical experiment. This translates as -}

1. If you do not agree to be an experimental subject, I will have you executed, and

\section{If you do agree, I will commute your sentence.}

It is clear that the governor is coercing the prisoner and we have good grounds for being sceptical about the voluntariness of consent that is given under these conditions. In some respects this is similar to how the option of castration could be presented to a sex offender. While they are not going to be executed, they are often facing indefinite detention so in one sense, this is a 'having a life' decision. There are similar levels of uncertainty about what taking the 'coerced' option will mean: it's not clear how dangerous or unpleasant the medical experiment would be, just as the consequences of being castrated might be difficult to know. The most important similarity is that both offers occur in a context where the 'coercer' has power over the 'coercee'.

While it's clear that the governor is threatening the prisoner and that this is key to this being an instance of coercion, it's less obvious that the offer in this case is a genuine offer, that is, one that is independent of a threat. The governor has the ability to commute the prisoner's sentence but she will only do this if the prisoner does what she wants. A psychiatrist who mentions the possibility of castration to a sex offender and then facilitates the process where by this is approved and provided does not have the same power to commute the sex offender. They might have the ability to communicate a judgment about the sex offender's suitability for release, so there could be cases where this power is used and a sex offender is threatened. However, it is reasonable to suppose that this power is not or only very rarely exploited. If the offer to commute the prisoner's sentence is not independent from the threat to execute him, then we might plausibly describe this as a coercive threat. While this would mean that it is still an instance of coercion, it would cease to be an 'offer'. Of course, more needs to be said about what it means to say that a threat is 'independent' of an offer and it is useful to contrast the governor and the prisoner with another case that teases this out. Perhaps the most famous example of a coercive offer is Feinberg's 'lecherous millionaire'.

Suppose opportunistic A holds out to unfortunate B the prospect of rescue or cure-but for a price. B is in an otherwise hopeless condition from which A can rescue her if she gives him what she wants. He will pay for the expensive surgery that alone can save her child's life provided that she becomes for a period his mistress. A thus uses his superior advantages to manipulate B's options so that she has no more choice than she would if a gunman pointed his pistol at her healthy child's head, and threatened to shoot unless she agreed to become his mistress. ${ }^{18}$

Like the prisoner, $\mathrm{B}$ is being coerced and has little choice but to do something that she has a strong preference against doing. As was the case for the prisoner and could be for some sex offenders, this choice occurs in a context where there is a radical disparity in power and vulnerability. The difference between the lecherous millionaire and the prisoner is that in the latter case the governor makes a threat and in the former, the millionaire does not. There's no doubt that he is exploiting B's vulnerability in a morally deplorable way but he is not responsible for B's dire situation or (arguably) for helping her out of it. While it would be good if he did pay for the expensive surgery with no strings attached he is not under an obligation, (at least one that would take the form of a perfect duty) to aid her in this way. For this reason his offer can be considered an offer and is not parasitic upon a threat.

There could be cases where sex offenders are threatened, that is, 'unless you consent to castration, I will not support your release' but it seems more likely that castration would be presented to them as an offer, for example, 'if you do this there is, as we both know, a greater chance that you will be released.' While this kind of offer is ruled out by the German policy it is something that could occur and is subtly different from a straightforward threat. Such a psychiatrist, like the lecherous millionaire, is not responsible for the bad situation that the sex offender is faced with, nor does he or she have an obligation to do something else to alleviate that situation. But if they used these background conditions in order to influence the sex offender's decision this could be coercive and it is therefore reasonable to worry about the possibility of this being a coercive offer.

There is another normative feature of these cases, over and above the voluntariness of consent. Bomann-Larsen ${ }^{19}$ describes the wrong-making feature of such offers as 'a violation of the other's fundamental claim to moral respect. If $\mathrm{A}$ is already wronged by the offer to $\mathrm{X}$, her consent to $\mathrm{X}$ cannot take the wronging out of X'ing her.' This claim seems correct, while sex offenders who are castrated and the millionaire's mistress might 
have given consent that was voluntary (in the sense that they were free to choose between more than option) and informed, they can still be wronged by taking up this offer even though it might have been rational, voluntary and made them better off than they would otherwise have been. Agreeing to become a mistress so as to pay for life-saving surgery is an action that is likely to cause moral harm to B. It might be that the offer itself, even if B does not agree to it, wrongs her. If she does not accept the offer she will know that she chose the option that could have saved her child, even though this would have harmed her. As Bomann-Larsen points out, the wrongness of these coercive offers has more to do with the wilful creation of choices that take advantage of others' vulnerabilities, and the wrong is that this fails to accord a fellow human being the moral respect they deserve.

It's important to mention that coercive offers are not uncontroversial and some think that Feinberg's example and the idea of a coercive offer undermining consent are 'false and incoherent'. ${ }^{20}$ Some of these critics are not sceptical about the existence and moral relevance of coercion, so in cases where coercive offers collapse into threats it can still make sense to describe this as a problem for consent. It is beyond the scope of this paper to defend coercive offers at length, however given that it does seem possible for people to be coerced without a coercer explicitly stating a threat, this is a possibility that we should consider carefully.

\section{THE BADNESS OF COERCED CASTRATION}

This analysis implies that there are three possible ways in which we might categorise the coerciveness of castrating sex offenders.

One kind of possible case is when a psychiatrist, or the state more generally, makes it clear that unless a sex offender takes up the offer of being castrated the psychiatrist or the state will do everything within their power to ensure that the sex offender is not released. That kind of case clearly involves a coercive threat and there is no reason to suppose that any threats of this kind are being made within the German or Czech systems.

A second kind of case is one that is more like the lecherous millionaire scenario where the psychiatrist who mentions the possibility of castration to a sex offender does so without any influence over whether he will only be released if he is not castrated, but also intends the fact that the state will not release him to be the operant reason for him accepting castration. We could (objections to the possibility of there being any coercive offers notwithstanding) describe this as a coercive offer. It is one that genuinely would increase the range of options open to the sex offender but which also relies upon the undesirability of indefinite incarceration to coerce him into being castrated. It's important to note that in that kind of case it could be that a psychiatrist makes a coercive offer but that the state via its legal system is in effect making a coercive threat. The legal system might have the power (as in the governor case) to release the sex offender and they could therefore implicitly be saying 'accept castration or you will not be released.'

\section{Are these two kinds of cases always wrong?}

There are some good reasons for thinking that coercion is essentially normative in the sense that it always involves a wrong of some kind. However, we should concede that there are occasions when there are other weighty moral considerations that mean coercion is justified. For example, a 6-year-old child who refuses to leave a department store unless her mother buys her a new doll might be convinced to leave with the threat that she will not have any bedtime stories unless she leaves now. This coercive threat satisfies all of Nozick's conditions and is a clearcut case of justifiable coercion.

While this is a relatively benign instance, this kind of coercion is fairly common in healthcare contexts. For example, a drop-in centre might be concerned about whether they can balance their competing obligations to eliminate smoking in the workplace and to let those using the centre make their own minds up and provide somewhere for them to smoke. Suppose that they have trouble confining smokers to a designated area outside and introduce a rule that those who smoke outside of this area will have to leave the drop-in centre for the rest of the day. This too seems like a coercive threat but one that, perhaps, could be justified.

Needless to say, being castrated and being confined indefinitely are much more serious outcomes and it is going to be more difficult to argue that coercion could be justified. Because this is a permanent physical alteration with significant implications for the person concerned, a sex offender should not be coerced into castration be that via a threat or an offer.

The third kind of case is when the possibility of castration is presented in a way that is not coercive. The lecherous millionaire takes advantage of a vulnerability so as to bring about something that he wants. A psychiatrist or state need not intend that sex offenders are castrated, nor the link with an earlier release function as a reason for a sex offender to be castrated. Of course, this does not imply that the possibility of controlling criminal sexual behaviour and the potential implications of that for being released early will play no role in the sex offender's reasons for wanting to be castrated, but why should that be an objection to them requesting this? If a sex offender forms an informed, competent and rational choice about what castration could mean for their ability to manage their life and be integrated back into society and this choice is not coerced, then there should be no voluntariness based objection to this occurring.

There is every reason to suppose that in the Czech Republic and Germany this is a voluntary choice and there is no coercion. Germany has gone to significant lengths to ensure that this is the case. In addition to the requirements already mentioned that only the person concerned can initiate this procedure and that there is formed consent, they also require that 'he must be informed that surgical castration does not entail entitlement to early release. ${ }^{8}$

Conditions such as these and the fact that in the case of Germany, less than five physical castrations per year have been performed over the last 10 years should lead us to conclude that the CPT's fears about the voluntariness of physical castration are unwarranted (CPT report). ${ }^{6}$ The situation with respect to the Czech Republic is a little more complicated in that (as has already been noted) the CPT interviewed some castrated sex offenders who claimed they were inadequately informed about side effects. However, it is also true that they also have a tribunal that must satisfy itself that the request for castration has come from the sex offender and that consent is valid.

Even if we are satisfied that the 'offer' of castration is not coerced there are a number of relevant moral considerations, such as this being the only way that many of these men will have a chance at freedom and whether they are in fact wronged by castration. In the following sections I consider a number of other relevant factors that will help in reaching a reasoned response. In the next section I will argue that the lack of alternative therapy in the case of the Czech Republic is a serious but not obviously decisive problem.

\section{PHYSICAL CASTRATION}

While the majority of European countries do not treat sex offenders by physically castrating them, chemical castration is 
offered to some sex offenders in many countries. The CPT note that some sex offenders are treated with antiandrogens in the Czech Republic but that the use of these drugs is constrained because of cost.

Antiandrogens were commonly administered in the psychiatric hospitals visited; at Kuřim Prison antiandrogens are only administered in the 6 months before transfer to a psychiatric hospital due to financial limitations. ${ }^{5}$

They suggest that antiandrogens can be an acceptable treatment when a number of conditions about treatment are met, such as it being offered only when a free and fully informed decision is made and when it is combined with other forms of treatment such as psychotherapy. Clearly, the CPT thinks that there are some fundamental differences between physical and chemical castration.

The side effects of antiandrogen treatment appear to be similar to physical castration, in that they tend to feminise the body and there is an increased risk of osteoporosis. Cyproterone acetate is often used to treat sex offenders and this has been shown to be associated with a risk of liver damage. ${ }^{21}$ A significant and obvious disanalogy is the permanence of physical castration and the reversibility of antiandrogen treatment. Of course, the reversibility of chemical therapy also opens up the possibility of non-compliance.

It would appear that a significant reason why the Czech Republic continues to offer a surgical solution is because they can't or won't fund antiandrogen therapy on an indefinite basis. If they genuinely cannot fund chemical castration then, it makes the case in favour of them continuing to offer surgical castration stronger. If, on the other hand, they could offer chemical castration as a treatment option then it is harder to make a case for them continuing to offer only physical castration. Given the permanent nature of the surgical solution, it seems reasonable that sex offenders should, if it is feasible to do so, be offered the option of controlling their offending with antiandrogen therapy.

The problem is that it's often very difficult to verify claims about the difficulty of funding particular treatments. Not being able to afford something is often a judgment about the opportunity cost, that is, what else can't be funded if this is. It's also relevant that not being able to fund something can be because an insufficient proportion of public funding has been allocated, a problem that might have a political solution. It's beyond the scope of this article to settle these questions, so for argument's sake I am going to take the claims of the Czech government at face value and assume that it is not economically feasible for them to supply antiandrogen therapy to sex offenders for an indefinite length of time.

While the use of antiandrogen therapy for controlling sex offenders is controversial, many would find the surgical solution galling. It might be that, to at least some extent, many are concerned by surgical interventions that have the potential to alter personality and others aspects of persons that are important to them being the kind of person they are. This might be the case, even when they are a sex offender and this is the issue explored in the following sections.

\section{CASTRATION AS A FORM OF PSYCHOSURGERY?}

At one level it's obvious that castration is not psychosurgery: this term is usually reserved for surgical interventions that cause brain lesions so as to treat mental illness. Nonetheless physical castration is surgery that tries to alter the psyche of the sex offender. In Gillett's terms, castration changes what is deep inside a person. ${ }^{22}$ Psychosurgery has, to put it mildly, a chequered past, in that very harmful operations were performed when very little was known about the profound damage that it could do. ${ }^{23}$ While early attempts at psychosurgery were highly experimental, testicular pulpectomy is a straightforward surgical operation and has been refined because of its utility for treating prostate cancer. It's also relevant that much more is known about the effects of a permanent reduction in testosterone. While brain lesions like those caused in early psychosurgery cannot be repaired, some of the effects of castration could, if there were a good reason to do so, be reversed by hormonal treatment.

\section{USING LIBERTY TO DEBASE LIBERTY}

Even if it is possible for a sex offender's consent to be valid it is possible to question whether this is an appropriate use of one's liberty. Mill is famous for the claim that we should not consider an agent's own good sufficient warrant for overriding their choices. However Mill thinks that there are some exceptions, such as a decision to sell oneself into slavery.

...By selling himself for a slave, he abdicates his liberty; he foregoes any future use of it, beyond that single act. He therefore defeats, in his own case, the very purpose which is the justification of allowing him to dispose of himself. He is no longer free; but is thenceforth in a position which has no longer the presumption in its favor, that would be afforded by his voluntarily remaining in it. The principle of freedom cannot require that he should be free not to be free. It is not freedom, to be allowed to alienate his freedom. ${ }^{24}$

Mill's point is that selling oneself into slavery is an act that involves using the right to liberty to forsake liberty. Slavery imposes physical constraints upon freedom while surgery that damaged or destroyed agency would undermine the preconditions of freedom. On the other hand, Mill's reasons for thinking freedom important could be undermined just as much by agency destroying surgery as are by selling oneself into slavery. For Mill freedom is important for individuality and experiments in living, and slavery frustrates these values. Is castration, which will inevitably lead to a broad spectrum of changes in a sex offender, consistent with reconfiguring individuality or is it an intervention that violates the integrity of that person? If freedom is essential because it enables agents to form and realise a plan of life, does castration frustrate this important end of freedom or could it be the springboard from which a damaged life can be reoriented? One way to get some purchase on these questions is to ask those who have been castrated.

\section{POSTSURGICAL ENDORSEMENT?}

In Wille and Beier's study of sex offenders, $70 \%$ of those who had opted for physical castration were satisfied with the intervention, while $20 \%$ were ambivalent and $10 \%$ not satisfied. ${ }^{13}$ What does this tell us? Postsurgical endorsement for other surgical interventions such as hip replacement or coronary artery bypass surgery can give us a fairly good idea about the improvement that these interventions can make to people's lives.

What's troubling about the postsurgical endorsement of castration is that it's likely that their view of the condition that they are now in has been coloured by the intervention that they've had. Admittedly, the changes in personality are not as radical as would be the case for a lobotomy, where we would have grave doubts about the usefulness of postsurgical endorsement. Nonetheless, the reason why castration is offered as an option is because it is hoped that it will help sex offenders to make significant changes to their desires, values and behaviour. 
Postsurgical endorsement gives some basis for thinking that this can be a good decision, but a broader view, whereby the trajectory and overall shape of a sex offender's life is taken into account is needed.

\section{THE TRAJECTORY OF ONE SEX OFFENDER'S LIFE}

In 1993 the British Medical Journal published the following case along with a series of commentaries by psychiatrists.

$\mathrm{Mr} \mathrm{K}$ is a 59 year old man with a long history of persistent sexual abuse against children. His abusive behaviour began when he was at school and continued into his marriage. He abused his own children, and, despite many periods of imprisonment, he continued to abuse children each time he was released. His last period of imprisonment was for 10 years. During that last period in prison $\mathrm{Mr} \mathrm{K}$ became determined to end his abusive behaviour and formed the idea that orchidectomy would solve his problem by curtailing his sex drive... While he was in hospital Mr K was offered chemical castration using goserelin but refused this because he regarded it as a temporary and incomplete solution. He wants a permanent solution to stop his abusive behaviour so that he can start to live a normal life. He is convinced that the operation will work and liberate him from his condition, which he compares to that of being a "leper." 25

In Julius Caesar ${ }^{1}$ Shakespeare suggests that the hurt done to Caesar by Brutus's betrayal was unkinder than Brutus slipping a knife into him. Mr K's sexual offending reveals a life history of betrayal and harm to those around him. This is a life with a guiding theme that is tragic and has damaged him profoundly as well as those who should have been able to trust him. His preference for an orchidectomy and refusal of chemical treatment mean that there is more to this preference than the wish to be free of overwhelming impulses or obsessions. As Gunn suggests in one of the commentaries, the reasons why $\mathrm{Mr} \mathrm{K}$ wants to be castrated are complex and the symbolism of this surgery is something that needs to be explored. ${ }^{26}$ However, it's not unreasonable to speculate that he thinks surgical castration is a way that he can radically change the kind of person that he is. Furthermore there's an important sense in which the way he wants to change would involve recalibrating his life so that he lives in accordance with acceptable values and desires. While there is no going back and his personal history cannot be changed, his wish to be castrated can be seen as a way to bring his life back onto a reasonable track.

However, there is an important issue implicit in this case surrounding the role of the passions and their relationship to agency and the kind of person one is. This article began by mentioning the dialogue at the beginning of the Republic about old age and what the calming of the passions can mean for the quality of a life. The implication was that the calming of the passions that follows the removal of most of the testosterone from a sex offender might make it possible for this person to begin a calmer, more reflective and less harmful period of his life. The passage quoted in the introduction continues as follows.

However, the one thing responsible for this, and for one's relationships with relatives as well, is not a person's old age, Socrates, but his character. If someone is self disciplined and good tempered, old age isn't too much of a burden; otherwise, it's not just a question of old age, Socrates-such a person will find life difficult when he's young as well. ${ }^{2}$

Plato's point is that whether or not the changes that old age brings are experienced as a burden depends upon the character of the person. The passions are an important aspect of a person's character but it is their cultivation and incorporation into a coherent and stable self conception that is important for living well. If a person struggles to cultivate and incorporate passions into a coherent self conception then the removal of those passions may or may not lead to revised conception of self. So even for those who do experience a calming of the passions postcastration, successfully transforming the kind of person they are involves more than this. $\mathrm{Mr} \mathrm{K}$ sees castration as a symbolic and psychological springboard for transforming the kind of person he is. However it's crucial to bear in mind that merely removing the desire to abuse might make a person milder and easier to contain but there is much more to the psychology of a sex offender than this.

If these (necessarily speculative) claims are correct then it suggests that when some sex offenders do succeed in reconfiguring their lives this has as much to do with them revising other aspects of themselves as it does to the removal of most of their testosterone.

These considerations are important if we are concerned to defend castration from the charge that this is simply a case of drugs or surgery being used to further socially useful ends. For castration to be considered a therapy it must do more than simply control reoffending and this is something that psychiatrists in Germany and the Czech Republic will think important. If sex offenders can use castration for broad psychological change and development, we should be less concerned about the fact that they have to make this choice against a background where their choices are limited.

\section{CONCLUSION}

It is difficult to adjudicate in the dispute between the CPT and the Czech government about the quality of the consent given by castrated sex offenders. Given the much lower number of castrations in Germany, their processes for governing this and that these objections were not made by the CPT to German practices, it is reasonable to conclude that this is not a problem in that country. Irrespective of the truth about practices within these countries, it is clear that the gravity of this decision is such that it should be taken on the basis of a clear understanding of the side effects, changes in personality and possible positive effects. Ideally, sex offenders should have the choice between chemical and physical castration but if it genuinely is the case that this is not possible in the Czech Republic then they should not be deprived of the option of surgical castration.

There are good reasons for being cautious about the potential coerciveness of the German and Czech systems and this is a serious ethical challenge. However, in cases where psychiatrists have good reasons for thinking that castration will lead to a transformation of self that is integrated and will enable sex offenders then castration might be the kindest cut. Leading a life in which the actions you perform are consistent with the considerations that you think you should act upon is one important aspect of agency. Despite the undeniable fact that chemical and physical castration are capable of changing people in ways that make most of us uneasy, when there are good reasons for predicting that it will result in a person being able to reconstruct their agency, then we should not view castration as cruel or inhumane treatment.

Acknowledgements I'm grateful to Adrian Walsh for pointing out the intriguing dialogue between Cephalus and Socrates at the start of the Republic. The two anonymous reviewers who read this paper for the JME made a number of useful suggestions that have improved it significantly. 
Competing interests None.

Provenance and peer review Commissioned; externally peer reviewed.

\section{REFERENCES}

1 Shakespeare W. Julius Caesar. Act III, Scene II. http://publicliterature.org/books/ julius_caesar/xaa.php (accessed 9 Feb 2010).

2 Plato. Republic. Oxford: Oxford University Press, 1993:5-6.

3 Sandel M. What's wrong with enhancement. The President's Council on Bioethics, 2002. http://www.bioethics.gov/background/sandelpaper.html (accessed 9 Feb 2010).

4 Parens W. ed. Enhancing human traits: ethical and social implications. Washington, DC: Georgetown University Press, 1998

5 European Committee for the prevention of torture and inhuman or degrading treatment or punishment. Report to the Czech Government on the visit to the Czech Republic carried out by the European Committee for the Prevention of Torture and Inhuman or Degrading Treatment or Punishment. Strasbourg: The Council of Europe, 2009.

6 European Committee for the prevention of torture and inhuman or degrading treatment or punishment. Report to the German Government on the visit to the Germany carried out by the European Committee for the Prevention of Torture and Inhuman or Degrading Treatment or Punishment. Strasbourg: The Council of Europe, 2012.

7 The Government of the Czech Republic. Response of the Czech Government to the report of the European Committee for the Prevention of Torture and Inhuman or Degrading Treatment or Punishment (CPT) on its visit to the Czech Republic from 25 March to 2 April 2008. Strasbourg: The Council of Europe, 2009.

8 The Government of Germany. Response of the German Government to the report of the European Committee for the Prevention of Torture and Inhuman or Degrading Treatment or Punishment (CPT) on its visit to Germany from 25 November to 2 December 2010. Strasbourg: The Council of Europe, 2012.

9 Burleigh M. Ethics and extermination: reflections on Nazi Genocide. Cambridge: Cambridge University Press, 1997:113-30.
10 Chodoff P. Misuse and abuse of psychiatry: an overview. In: Bloch S, Chodoff P, Green S. eds. Psychiatric Ethics. Oxford: Oxford University Press, 1999:49-66.

11 Gordon H. The treatment of paraphilias: an historical perspective. Crim Behav Ment Health 2008:18:79-87.

12 Cendrowicz L. The unkindest cut: a Czech solution for sex offenders. TIME, 11 Feb 2009.

13 Wille R, Beier K. Castration in Germany. Sex Abuse 1989;2:103-33.

14 Losel F, Schmucker M. The effectiveness of treatment for sexual offenders: a comprehensive meta-analysis. J Exp Criminol 2005;1:117-46.

15 Nozick R. Coercion. In: Morgenbesser S, Suppes P, White M, eds. Philosophy, science, and method: essays in honor of Ernest Nagel. New York: St Martin's Press, 1969:440-72.

16 Sjöstrand M, Helgesson G. Coercive treatment and autonomy in psychiatry. Bioethics 2008;22:113-20.

17 Prinssen $E$, van Delden J. Can we justify eliminating coercive measures in psychiatry? J Med Ethics 2009;35:69-73.

18 Feinberg J. Harm to self: the moral limits of the criminal law. Oxford: Oxford University Press, 1986.

19 Bomann-Larsen L. Voluntary rehabilitation? On neurotechnological behavioural treatment, valid consent and (In)appropriate offers. Neuroethics 2013;6:65-77.

20 Wertheimer A, Miller F. Payment for research participation: a coercive offer? J Med Ethics 2008;34:389-92.

21 Scott C, Holmberg T. Castration of sex offenders: prisoners rights versus public safety. J Am Acad Psychiatry Law 2003;31:502-9.

22 Gillett G. Psychosurgery. In: Ashcroft R, Dawson A, Draper $\mathrm{H}$, et al. eds. The principles of health care ethics. Chichester: John Wileys, 2007:811-17.

23 McMillan J. Psychosurgery. LaFollette $\mathrm{H}$, ed. In: International encyclopedia of ethics. Oxford: Wileys Blackwell, 2013, 1-6.

24 Mill JS. On liberty. New York: P.F. Collier and Son, 1909 [1859]. Ch 5.

25 Malcom A. Ethical considerations in using orchidectomy for social control. BMJ 1993;307:790.

26 Gunn J. Castration is not the answer. BMJ 1993:307:790-1. 